\title{
APROXIMACIÓN A LA CONTABILIDAD DEL CONVENTO DE SANTA ISABEL DE AREATZA COMO INDICATIVO DE LA COYUNTURA ECONÓMICA DE BIZKAIA (1680/1885)
}

\author{
Jürgen Lange ${ }^{1}$ y Mikel Zabala ${ }^{2}$
}

\section{Introducción}

El título del presente artículo sintetiza las pretensiones de los autores del mismo; toda vez que se intentará, mediante el análisis de determinada seriación de precios de una villa vasca, discernir las variaciones puramente coyunturales de aquellas más profundamente estructurales en su devenir histórico antiguorregimental. Y es que, a nuestro entender, modificaciones en el valor del dinero o, si se prefiere, en la capacidad adquisitiva general, pueden estar evidenciando tanto variaciones en las costumbres alimentarias, como transformaciones productivas, alteraciones en el sistema monetario, etc.

Como quiera que la revolución de los precios se retrotrae a fechas anteriores a las del objeto de nuestro análisis, su consideración previa será inevitable por cuanto mediatiza sobremanera los modelos teóricos sobre los que se sustentará aquél ${ }^{3}$.

Serán los economistas peninsulares del Quinientos de la llamada Escuela de Salamanca los pioneros en el estudio de su coetáneo incremento sostenido de los precios. Así, ya desde 1557, el clérigo de Barasoain Martin Azpilicueta teorizó sobre la relación entre mercancía y moneda:

"Todas las mercaderías encarecen por la mucha necessidad que ay, y poca qantidad dellas; $y$ el dinero en quanto es cosa vendible, trocable o conmutable

1. Doctor en Historia por la Universidad de Siegen. Profesor de la Universidad de Deusto.

2. Doctor en Historia por la Universidad de Deusto.

3. No pretendemos, evidentemente, a partir de las páginas subsiguientes la elaboración de un nuevo modelo; sino, antes bien, únicamente considerar y cuestionar los preexistentes... 
por otro contrato, es mercadería, por lo susodicho, luego también él se encarece por la mucha necesidad y poca qantidad dél..." ${ }^{4}$.

Cuestión sobre la que fray Tomás de Mercado, por su parte, se expresaba, a la altura de 1568, en los siguientes términos:

“...que en Indias vale el dinero lo mesmo que acá (conviene a saver) un real treynta y quatro maravedís, un pezo de minas treze reales y lo mesmo vale en España, mas aunque el valor y precio es el mesmo, la estima es muy diferente en entrambas partes. Que mucho menos se estima en Indias que en España (...) La qual estima y apreciación es causa lo primero, de tener gran abundancia o penuria de estos metales, y como en aquellas partes nasce y se coge, tiénese en poco $(\ldots)^{\prime \prime}$.

En parecidos términos se expresan Luis de Saravia, Luis Ortiz, etc. La lista se podría, pues, prolongar sin sustantivas variaciones.

Desde otro contexto, el francés Malestroict ya había dado cuenta en 1566 de la relación entre envilecimiento monetario e incremento de precios; cañamazo sobre el que los teóricos franceses del Bullonismo sustentarían su defensa de la creación de un Tesoro Público garante de unos fondos en metales preciosos, así como su oposición a la extracción de tales metales de los límites del Estado.

Muy diferente argumentación al respecto ofrecería Jean Bodin en La réponse de Jean Bodin à M. de Malestroict, donde se descalifica la creencia de este último en el paralelismo entre aumento de precios y envilecimiento monetario. A juicio del abogado en Corte:

"Todo es más caro en España que en Italia, y en Italia que en Francia, incluso el servicio y mano de obra, ya que lo que atrae a nuestros auverneses y limosines hacia España, como yo mismo he comprobado, es que ganan tres veces más que en Francia. Porque el español, altivo, rico y perezoso, vende su trabajo muy caro (...) Es por tanto la abundancia de oro y de plata lo que, en parte, causa la carestía de las cosas"

Dicotomizada, pues, la cuestión en las dos posturas referidas ya desde entonces, numerosas han sido las aportaciones recibidas con posterioridad. Entre todas las cuales únicamente mencionaremos la velocidad de circulación de la moneda, variable introducida por John Locke en $1692^{7}$.

4. Cf. P. VILAR (1983: 135-162).

5. TOMÁS DE MERCADO: Suma de tratos y contratos. Libro IV De Cambios, fo 30 ro , SeviIla, 1571. Es la edición manejada por P. VILAR (1983: 141), fuente para nuestra reproducción del extracto.

6. Fuente citada en P. VILAR (1972: 122).

7. Elemento no abordado en el presente artículo tanto por las dificultades en la determinación de la velocidad de circulación monetaria en un momento histórico concreto; cuanto por la presunción de los teóricos modernos de una constante en la velocidad de la circulación a largo plazo... 
Al presente, la historia de los precios se bipolariza en torno a dos escuelas: Cuantitativismo vs. Fiscalismo ${ }^{8}$. Heredera del legado teórico de Bodin, defiende la primera una relación directa entre incremento del monto monetario circulante y aumento general de los precios; en tanto la segunda prioriza el aumento de la demanda autónoma, basada en los bienes y servicios necesarios para la supervivencia.

Centro de interés de ambos modelos resulta la inflación; sobre la que parece haber un cierto consenso en cuanto a la necesidad de incremento de la masa monetaria circulante para la existencia de inflación prolongada. Pero el Cuantitativismo propugna el ingreso nacional a determinado nivel de precios y la velocidad de circulación del dinero como factores determinantes del monto monetario circulante en una economía nacional, presuponiendo que el incremento en la cantidad de dinero conlleva el de la demanda monetaria por unidad productiva; de donde se sigue un necesario aumento de la producción o bien de los precios (caso éste último acontecido durante la revolución de los precios del Siglo XVI). Planteamiento al que, de acuerdo con el Fiscalismo, habría que adicionar la variable demográfica (creciente demanda autónoma de bienes de consumo, para el período referido).

Entre los últimos veinte y los primeros años treinta, una serie de autores aportaron grandes cantidades de datos referentes a la evolución de los precios en el Antiguo Régimen: E.J. HAMILTON: El tesoro americano y la revolución de los precios en España 1501/1650; E. LABROUSSE: Fluctuaciones económicas e historia social; y W. ABEL: Agrarkrisen und Agrarkonjunktur. Estos dos últimos subrayaron en sus respectivos trabajos la importancia de la evolución demográfica en relación con las alteraciones de los precios, diferenciando los movimientos cíclicos estacionales de los interanuales y de los de larga duración. A corto plazo, era la oscilación en la cosecha el elemento determinante en la modificación en los precios; en tanto a medio y largo plazo lo sería la evolución demográfica9. La crisis de tipo antiguo fue caracterizada por E. LABROUSSE como el resultado de la sustitución en el consumo de productos de mayor categorización social por otros inferiores ${ }^{10}$. E.J. HAMILTON, por su parte, atribuyó a la importación de metales preciosos el incremento en los precios de los Siglos XVI/XVII.

En síntesis, el estudio de la evolución de los precios puede diferenciarse en dos grupos principales de acuerdo con la variable priorizada:

8. Las líneas que a continuación siguen no son sino un breve extracto de ambos modelos, para cuya precisa contextualización se deberá recurrir a las fuentes bibliográficas de ellas inspiradoras: R. PIEPER (1985: 67-82), P. VILAR (1972: 122), y R. METZ (1994: 223-234).

9. W. ABEL (1974: 34-42).

10. E. LABROUSSE (1980: 135-138). 
- Relación oferta/demanda (variaciones en la cosecha, en el volúmen poblacional, etc.).

- Alteraciones en el sistema monetario (importación/exportación de metales preciosos, envilecimiento monetario, etc.).

Por nuestra parte, hemos seleccionado un período de escasas alteraciones en el sistema monetario (en relación con la anterior centuria); de modo que aun cuando persistirá su influjo, éste ya no constituirá el factor determinante. No es posible ya, pues, afirmar que "las abundantes minas de América fueron la principal causa de la revolución de los precios en España"11. El envilecimiento monetario, por otro lado, tampoco afecta excesivamente al período de nuestro estudio hasta la fundación en 1782 del Banco Nacional de San Carlos.

En cuanto a la incidencia de las malas cosechas, desastres naturales, guerras, etc., por el contrario, cabe suponer su reflejo en las series obtenidas en forma de breves oscilaciones de gran amplitud.

Nuestro objetivo en el presente estudio es muy otro. Resulta lógica, a medida que nos aproximamos a la Contemporaneidad, la aparición de nuevas variables, entre las que señalaremos las innovaciones agropecuarias o las modificaciones en la infraestructura comercial. Objetivo para el cual nos centraremos en el análisis de los precios de los Libros de Cuentas de la Comunidad de Santa Isabel de Areatza; metodología de trabajo ya iniciada con anterioridad -J. LANGE (1996: 191-196)-. En esta ocasión se estudiará una mayor serie temporal y una más amplia y variada oferta productiva ${ }^{12}$. Partiendo de su agrupación en tres grupos en función de los circuitos de transporte, se ha buscado analizar no sólo las causas de las oscilaciones, sino -a diferencia de los anteriores autores- su reflejo o instrumentalización en las transformaciones económicas reales.

\section{Areatza: rasgos generales}

Municipio desgajado de Zeanuri' ${ }^{13}$ en 1338.VIII.15 - Villa de Haro ${ }^{14}$-, de donde toma, en virtud de la correspondiente fundación señorial por Juan Núñez de

11. E.J. HAMILTON: El tesoro americano y la revolución de los precios en España 1501/1650, aquí citado según J. NADAL OLLER (1959: 515), de quien procede el subrayado, que igualmente hacemos nuestro.

12. Vía, incomprensiblemente, en absoluto trabajada. Resulta paradójico que fuese esta, precisamente, la metodología utilizada por el propio E.J. HAMILTON (1988: 121 ss.). Algunos estudios en base a fuentes eclesiásticas lo han sido sobre documentación del clero secular, de muy diferentes características a las aquí presentadas -J.M. CIFUENTES PAZOS (1994); E. CATALÁN MARTÍNEZ (1995)-; o -caso de documentación conventual- con unos objetivos muy diferentes a los aquí propuestos -M.A. BARCENILLA (1985).

13. J. YBARRA Y BERGÉ (1967: 253).

14. En realidad, el núcleo urbano vería, a no tardar, modificado su primigenio emplazamiento en las proximidades de la tejera de Arenaza (en razón de la insalubridad del enclave) para reconstruirse en el actual. J.R. ITURRIZA (1985: 822). 
Lara y doña $M^{\text {a }}$ Díaz de Haro, el estatuto villano que la distingue jurídica, y por extensión económicamente (léase, legislación civil castellana, designación propia de autoridades privativas ${ }^{15}$, y disponibilidad de mercado, respectivamente) del entorno circundante. Enclavado en el fondo de la Merindad de Arratia, su marginalidad con respecto a otras vías de comunicación de Bizkaia pudo ser la clave para la imposibilidad de superación de unas dimensiones más que modestas en el conjunto del Señorío. He aquí algunas:

\begin{tabular}{|c|c|l|}
\hline Fecha & № Habs. & Fuente \\
\hline 1787 & 610 & I.N.E. (1988) \\
\hline 1797 & 611 & A.H.D.B.: Secc.Adm.: Estadísticas de Población: Reg. 50 \\
\hline 1802 & 615 & A.H.D.B.: Secc.Adm.: Estadísticas de Población I: Reg. 24 \\
\hline 1810 & 593 & A.H.D.B.: Secc.Varios: Libros Históricos № 128 \\
\hline 1813 & 562 & A.H.D.B.: Secc. Adm.: Estadísticas de Población I: Reg. 24 \\
\hline 1825 & 728 & A.C.J.G.: A.B.: Estadísticas de Población: Censo de Policía: Reg. 20 \\
\hline 1997 & 1096 & \multicolumn{2}{|l}{} \\
\hline
\end{tabular}

Las labores de transformación del herraje y clavazón en forma de pequeñas fraguas domésticas caracterizarían a nuestra villa buena parte del Antíguo Régimen, en consonancia con otros núcleos del eje comunicacional con Gasteiz, tales como Otxandio o Ubidea ${ }^{16}$. Para la segunda mitad del Setecientos, sin embargo, debieron éstas actividades de atravesar un período de decadencia. Así que si todavía en el cambio de siglo VICENTE GONZÁLEZ ARNAU contabilizaba nueve fraguas de herraje ${ }^{17}$, mediada la centuria, PASCUAL MADOZ no referiría ninguna ${ }^{18}$. Liquidación industrial de la villa que en absoluto desvirtuó su naturaleza diferencial de villazgo. El Censo de 1797 registra 4 escribanos y 24 jornaleros, a pesar de la presencia de tan solo 10 artesanos $^{19}$. El Censo de 1825 , por su parte, arroja un porcentaje poblacional del 29,5\% dedicado a la siderúrgia -frente a, por ejemplo, un 41 \% para Ubidea-, si bien con un 44,9 \% insertado en diversas otras categorías socioprofesionales (hecho éste que será para F. RAMOS el síntoma distintivo de Areatza en relación con el ambito cir(cundante) $)^{20}$.

15. De acuerdo con sus dimensiones, el sistema electoral de Areatza apenas desarrolló normativas oligarquizantes, siendo la elección anual de ediles por cooptación de la totalidad de los propietarios. Cf. F. MARTíNEZ RUEDA (1994: 46).

16. Una serie de precios de hierro para Areatza en el Setecientos ya fue publicada por R. URIARTE AYO (1988: 218).

17. REAL ACADEMIA DE LA HISTORIA (1980: 457).

18. P. MADOZ (1990: 206).

19. A.H.D.B.: Secc. Adm.: Estadísticas de Población I: Reg. 50.

20. F. RAMOS (1987: 160). 
Sea como fuere, la crisis del Antiguo Régimen debió, en cierta manera, de arrastrar consigo la captación del mercado del entorno, cuya oferta -acaso- se desviaría hacia otros núcleos: de ahí que a la altura de 1800 haya desaparecido el antiguo mercado que otrora se celebraba semanalmente y por festividad de San Bartolomé (quedando reducido a los ocho siguientes a San Miguel), en contravención a los ritmos marcados en el contexto general de Euskal Herria por las mismas fechas ${ }^{21}$. Y es así que durante el Ochocientos nuestra villa adquiriría definitivamente la fisonomía agropecuaria que ha mantenido inmutable hasta el presente: "Villaro es un pueblo completamente agrícola" aseveraba M. AZCARRAGA hacia $1885^{22}$.

\section{La comunidad de Santa Isabel de Areatza ${ }^{23}$}

Físicamente emplazada en Zeanuri ${ }^{24}$, la Comunidad de Religiosas Clarisas de Santa Isabel de Areatza sumerge sus orígenes en la oscuridad documental altomoderna. Data J.R. ITURRIZA la formalización en clausura de un primigenio beaterio en $1620^{25}$; fecha en torno a la cual, y en consonancia tal vez con la modificación en la normativa comunitaria, se nos presentan los primeros testimonios escritos de la misma. Ni qué decir tiene, de cualquier modo, la consustancial vinculación entre comunidad regular y mundo urbano. Generación de excedente, amplitud de demanda varia, actividades extra-agropecuarias, o mercado crediticio son algunos de estos nexos.

Es evidente que un análisis económico de la Comunidad en sí misma desbordaría sobradamente los límites del presente artículo. Baste señalar, en todo caso, la lógica proporcionalidad entre las dimensiones urbana y comunitaria, si bien la ausencia de religiosas en un ámbito espacial relativamente ámplio -únicamente La Merced de Ibarra (Orozko) se nos presenta en los alrededoresamplifica la proyección espacial del mismo. No es de extrañar, pues, que tanto en efectivos humanos cuanto en demanda de capitales se extendiera por buena parte del Valle de Arratia ${ }^{26}$. Conocemos -si bien para tiempos tardíos- las dimensiones de Santa Isabel:

21. E. FERNÁNDEZ DE PINEDO (1974: 234).

22. J.R. ITURRIZA (1985: 825). El texto corresponde, sin duda, a la reedición de M. AZCARRAGA REGIL del ejemplar de J.R. ITURRIZA de Munitibar.

23. Salvo indicación contraria expresa, y a los efectos de aligerar el aparato erudito de los piés de página, las citas insertadas en adelante corresponden al Archivo de este Convento. Desde aquí queremos hacer constar la buena disposición -demostrada igualmente en circunstancias anteriores- de la Comunidad para la consulta de sus ricos fondos documentales.

24. REAL ACADEMIA DE LA HISTORIA (1980: 457) ó P. MADOZ (1990: 206).

25. J.R. ITURRIZA (1985: 823), fechas análogas, por otro lado, con numerosas comunidades del conjunto territorial de Bizkaia, como se puede recoger en el conjunto de la obra del historiador de Berriz.

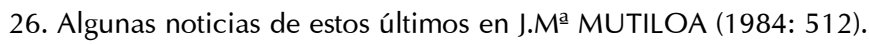




\begin{tabular}{|c|c|l|}
\hline Fecha & NoReligiosas & Fuente \\
\hline 1787 & 18 & I.N.E. (1988) \\
\hline 1797 & 12 & A.H.D.B.: Secc.Adm.: Estadísticas de Población I: Reg. 50 \\
\hline 1809 & 11 & J.M. ${ }^{\text {a }}$ MUTILOA (1984) \\
\hline 1828 & 14 & A.H.C.S.I.A. ${ }^{27}$ \\
\hline 1837 & 12 & Ibid. \\
\hline 1845 & 8 & Ibid. \\
\hline 1859 & 15 & Ibid. \\
\hline 1869 & 19 & Ibid. \\
\hline 1874 & 15 & Ibid. \\
\hline 1884 & 22 & Ibid. \\
\hline
\end{tabular}

Las oscilaciones permiten intuir profundas variaciones en la composición de la Comunidad que, insistimos, hacen del análisis del conjunto de las estrategias del gasto un objeto de análisis tan rico cuanto difícilmente tangible en profundidad en el espacio disponible en estas páginas.

Aunque también ténue, podemos igualmente aportar alguna referencia del potencial económico del mismo, en función de los bienes desamortizados, en concomitancia con otras comunidades alejadas de los más populosos núcleos de Bizkaia ${ }^{28}$. El ingreso en la Comunidad, sin embargo, supondría un desembolso económico fuerte para la familia de orígen, y probablemente no accesible para el conjunto de los arratianos: de parte de Sor $M^{a}$ J Josefa se entregó en 1825.VIII.12 una dote de mil ducados ${ }^{29}$. Ignoramos, por el contrario, la riqueza atesorada en forma de objetos preciosos. A falta de inventarios, solamente detectamos de manera fugaz su existencia, con ocasión de los apuros para su preservación a raíz de la presencia del francés: en 1813.XII “...por limpiar la plata de nuestra iglesia por aber deslucido bajo de la tierra por miedo de los franceses huvo de gasto 158 reales".

27. Referencias siguientes a partir del número de bulas adquiridas por Semana Santa. No se recogen todas las oscilaciones en la nómina de la Comunidad, sino únicamente las principales, dado que el fallecimiento de alguna profesa con cierta asiduidad marcaba continuadas oscilaciones...

28. J.Mํ. MUTILOA (1984: 43 y 512).

29. Análoga cifra nos aparece en La Merced de Abando (A.H.C.S.J.L.: Libro de Ingresos y Gastos 1796/1853). En Sto. Domingo de Lekeitio, por las mismas fechas, las entregas oscilaban entre los 800 y los 1.300 ducados (A.H.C.S.D.L.: Libro Becerro, 1799/1833); de donde cabe cuestionarse la traducción intramural de las diferencias en los niveles económicos individuales previos... Huelga insistir en agradecimientos hacia las actuales titulares de la documentación histórica de la referida comunidad de Abando. 
Las estrategias del gasto son fiel reflejo de tal nivel económico. De lo que nos ponen al corriente el consumo de carne, trigo, aceite o cera más o menos sistemático; así como la fabricación de repostería ${ }^{30}$. Porque, a diferencia del régimen alimenticio del común del Valle de Arratia, las compras de maíz iban destinadas al alimento de los cerdos y la volatería del Convento ${ }^{31}$. Y es que la crianza de dos o tres "cerdudos" o "gruñientes" (incluso cinco en los mejores años) ${ }^{32}$ adquiridos a principios de año permitía el enriquecimiento por San Martín de la despensa para una buena parte del año siguiente. Cecina, chorizos o morcillas serían, pues, un atractivo complemento para la mesa conventual. Matanza que con frecuencia se completaba con la de algun bóvido viejo, como en 1685.XII:

“...hubo de gasto con los vientres de los gruñientes y matanzas de gutrales y el dia de Pascua 20 reales y en esta forma: primeramente 6 reales y medio de pimienta (...) la canela y clavo; 6 reales de azucar que con los 6 de la matanza de los gutrales y vino del carnicero montan los dichos 20 reales".

Por lo que hace al consumo de vino, desconocemos la cantidad exacta que ingeriría diariamente cada religiosa. Tal vez no anduviese demasiado alejada del medio azumbre diario con que se agasajaba al Vicario durante sus estancias. En 1752.XI.30, por otro lado, se había sancionado:

"Que a las novicias no se les administre mas vino ni racion que a las religiosas profesas por ser abuso lo contrario".

De igual modo, la ración diaria de carne alcanzaría media libra:

"Que a las religiosas se les administre media libra de vaca, a cada una sin que de estas raciones se gaste para la criada ni para otra persona".

El cumplimiento preceptivo de la abstención del consumo de carne fue observado durante buena parte del perído de nuestro estudio. La reducción en la partida mensual de carne así lo refleja ${ }^{33}$ :

\begin{tabular}{|c|c|c|c|c|}
\hline Febrero & Marzo & Abril & Mayo & Junio \\
\hline 213 & 50 & 50 & 206 & 220 \\
\hline
\end{tabular}

30. La descripción del régimen alimenticio aquí expuesto puede contrastarse con la -probablemente no poco optimista- de F. LE PLAY (1990: 134-135) para una familia de pescadores en Donostia en 1856.

31. En alguna ocasión también se entrega en agasajo del Padre Visitador.

32. En 1708.XII: "Ytem pesaron los cuatro cerdudos 502 libras que costaron con sus matanzas en todo 371 reales y medio" . Pero, a diferencia de la anterior, rara vez se anota el peso; de modo que hemos desechado su análisis.

33. Año 1685. Cantidades expresadas en libras. 
De hecho, los mencionados Decretos de 1752.XI.30 ordenaban su observancia:

"Que los dias de vigilia se administre una libra de bacalao entre cuatro religiosas con aceite correspondiente para su condimento y a las que no pudieren comer bacalao se las administre un par de huevos"

A partir de 1819 tal precepto será redimido mediante la sistemática compra de bulas, que -a 2 reales/unidad-permitirá el consumo de carne a la Comunidad, y -en ocasiones- al propio Vicario.

Es indudable, por otro lado, el aprecio que ciertas actividades artesanales de las religiosas tendrían en el entorno láico. Así, en 1805.I don Ambrosio de Eguia, gestor fiscal de la Comunidad "porque hizo e no quiso llevar los derechos por las asesorías que esta comunidad sigue en pleito (recibió) 52 reales, a saber: un par de calzetas finas y bizcocho y tartas". No es un hecho excepcional: igualmente en 1812.IV "se han gastado en estos 26 meses con varias personas bienechoras 109 reales de bizcochos en consultas de abogados sobre contribuciones, e a más se le dieron un par de calcetas finas a (Fray Pedro Antonio de) Ynchaurbe (Vicario) en agasajo". A lo que vemos, la superposición de servicios y donaciones varios convergían en una amalgama de reciprocidades y contraprestaciones que dificultan la percepción desde la perspectiva actual $-\mathrm{O}$, si se prefiere, de los testimonios documentales- de la economía antiguorregimental de Santa Isabel.

Reiteramos, empero, la creencia en la profunda imbricación de los valores del mundo civil en el seno de la Comunidad. Y no ya únicamente desde la perspectiva de quienes encontraban en la iglesia una solución alternativa para vástagos no insertables en la compleja trama del mercado matrimonial ${ }^{34}$-recuérdese, en este sentido, la análoga nomenclatura (toma de estado) empleada por los contemporáneos para ambas disposiciones- sino también a través de los propios comportamientos de algunas de las religiosas profesas, de acuerdo con las normas dimanadas de la Visita de 1755.XI.30:

“...se manda a la madre abadesa guarde equidad y ponga orden en dicha conmutacion (de hábitos) atendiendo a la necesidad de dichas religiosas desterrando el abuso que se puede originar conmutando algunas religiosas sin necesidad llevadas solo de la codicia y asi se manda a todas las religiosas no puedan conmutar habitos ni ponerlos para este efecto fuera del convento sin expresa licencia de la madre abadesa quien debera procurar no se pongan en tiendas"

34. Significativo es, en otro contexto, el ámplio dominio de los Zabala del convento de Santa Susana de Durango durante buena parte del Seiscientos. He aquí la relación de Superioras del mismo: Angela Zabala, 1633.XII.15. Ma San Nicolás Zabala y Churruca, 1670.I.21. Ursula Clara Zabala, 1701.IX.26. Fuente: A.H.P.B.: Notariado: Legs. 72, 126 y 151 respectivamente. Esta pesquisa a partir de la documentación de la propia Comunidad de Religiosas de Durango nos ha sido, desgraciadamente, negada. 
Abuso que, cometido desde tiempo atrás, no remitía. De hecho, ya se había sancionado en la anterior Visita de 1752.XI.30: "Que no permita la madre abadesa que las religiosas comuten mas habitos que los precisos para vestirse con la limosna de los viejos".

Contravención de la normativa conventual extensible igualmente a la repostería. Porque bien que en esta visita se preceptuase:

"Que ninguna religiosa se escuse de asistir a las horas del coro con el pretexto de hacer bizcocho para sí en particular".

En 1755.XI.30 la amonestación íba a adquirir todavía mayor rotundidad:

“...se manda a la madre abadesa destierre la ambicion de hacer dulce las religiosas particulares y solo conceda que puedan hacerlos para regalarlos a sus parientes y bienhechores y a las religiosas que tuvieren alguna necesidad solo lo que bastare para remediarla. Y exorta su P.r. a todas las religiosas se abstengan cuanto les fuere dable de semejante comercio y trabajo".

La medición de la producción repostera de la Comunidad es materia que, por desgracia, se nos escapa por completo. Y es que uno de los indicativos más llamativos de esta orientación del Convento, como lo es la compra mensual de huevos - reiterada, practicamente, sin solución de continuidad a lo largo de todo nuestro período de estudio, y en importantes cantidades en función del valor de la partida- no permite el seguimiento regular de la misma, amén de las distorsiones que las también desconocidas variaciones numéricas en el corral de las religiosas nos añadiesen ${ }^{35}$. Digamos que en 1680.I se adquirieron 18 docenas a 1,4 reales/docena; en tanto al mes siguiente fueron 13 docenas a 1 reales/docena ${ }^{36}$.

No nos fue posible discernir una evolución en el consumo repostero de la Comunidad: chocolate, bizcochos, tostadas (en "Carnestolendas") o dulces varios se superponen de manera desordenada y -aparentemente- descuidada en los Libros de Cuentas. Pero las adquisiciones de azucar, canela, almendras, pasas, etc. no remitirán nunca. Aquí se nos presentan análogas dificultades a las advertidas con los huevos; puesto que ¿en que medida puede ser el azucar exponente de la producción repostera, toda vez que sabemos disponían de colmenas propias ${ }^{37}$ ?

Además del gasto alimentario, la iluminación sería probablemente otro distintivo de la Comunidad en relación con el conjunto de los habitantes de Are-

35. Tampoco se olvide el consumo directo de huevos con otros fines en tiempos de Cuaresma, convalecencia, etc. (cf. supra).

36. Precio éste último equivalente al que compraba la Comunidad de Dominicas de Lekeitio a la altura de 1756. A.H.C.S.D.L.: Libro de Gastos 1756/1850. No podemos menos que agradecer profundamente a esta Comunidad las facilidades y atenciones dispensadas en todo momento para el estudio de su valioso archivo, que será objeto de mayor atención en otra ocasión...

37. 1818.V: "...se le tomaron tres colmenas a 59 reales cada una a Juan de Balsola para en cuenta de los réditos". 
atza, dado que -además de para los oficios religiosos- las monjas debieron de disponer de sistemas de iluminación propios, según parece desprenderse de la Visita de 1752.XI.30:

"Que en el verano despues de las nueve de la noche se retire cada religiosa a su celda y en el invierno despues de las ocho y media para que asi se guarde el silencio debido".$^{38}$

Claro que disponibilidad de medios no era sinónimo de administración negligente o de gasto desmedido, como recoge la misma fuente:

"Que no permita la madre abadesa a las sacristanas gastar en dias solemnes ni en otros mas cera en los altares ni aranas que la precisamente necesaria".

\section{Análisis de los precios}

Las series de precios tomadas de los Libros de Cuentas de Santa Isabel de Areatza corresponden a carne de vaca, vino, trigo, maíz, aceite, bacalao, chocolate y cera. La conversión de diferentes unidades de medida nos generó numerosos problemas en razón de las equivalencias. El aceite demostró las limitaciones del estado de conocimiento en la materia. Y es que -por una parte- la relación libra/arroba oscila en determinadas fechas ${ }^{39}$, tal y como se muestra en el cuadro siguiente ${ }^{40}$ :

\begin{tabular}{|l|c|c|c|c|}
\hline Fecha & Cantidad & Precio (rs/arroba) & Total (rs) & Equivalencia libra/arroba \\
\hline 1718.X & 3 arrobas 14 libras & 39 & 139 & 24,80 \\
\hline 1724.II & 3 arrobas 16 libras & 29 & 109 & 21,09 \\
\hline 1724.IX & 3 arrobas 15 libras & 30 & 108 & 25 \\
\hline 1730.II & 12 arrobas 6 libras & 25 & 306 & 25 \\
\hline
\end{tabular}

El empleo de pellejos de aceite, por otro lado, es igualmente problemático, toda vez que la capacidad del continente varía ${ }^{41}$ : en 1703.XII: "un pellejo de

38. En ocasiones aparecen compras de lámparas: así, en $1720 . \mathrm{VI}$ se adquirieron dos candiles a tres reales cada. Para mayor información sobre el particular, J. LANGE (2000: 335-360).

39. Teniendo en cuenta la utilización indistinta de ambas unidades en gran parte del período estudiado, se ha optado por la asignación del valor 25 en aquéllos casos en que la equivalencia no se ha podido verificar en la propia partida individualizadamente. Problema que también tuvo que afrontar E.J. HAMILTON (1988: 138-139).

40. Aun más: en ocasiones hemos detectado errores en las sumas de las partidas, que -por supuesto- añaden una mayor incertidumbre a todo lo anterior. Entre otras, en 1695.VIII: "...costaron 6 fanegas y media de trigo 129 reales; sus precios, las 4 fanegas a $261 / 2$ y las otras dos restantes a $24^{\prime \prime}$.

41. Dificultad solventada en aquellos casos en que se insertaba el valor de la partida y el equivalente en libras o arrobas del pellejo; lo que, lamentablemente, no ha sucedido siempre. 
aceite pesó 83 libras son 127,5 reales"; en 1704.VIII: "un pellejo de aceite por valor de 155 reales"; mientras en 1707.IV: "un pellejo de aceite (...) 5 arrobas".

Muy diferente cuestión se plantea con las unidades monetarias, donde el mantenimiento de un número relativamente reducido de monedas -ducados, reales y maravedis- con equivalencia fija sin solución de continuidad a lo largo de todo el período estudiado facilita sobremanera los cálculos. Somos conscientes, por supuesto, del carácter ocasional de moneda de cuenta de las anteriores, puesto que junto con ellas circularían distintos módulos de doblones, pesos, escudos, coronas, etc. ${ }^{42}$ Discernir un uso del otro es labor escasamente factible $y$, por nuestra parte, ni siquiera planteada.

La periodicidad en la adquisición de los referidos productos (o en el registro de su precio) no nos ha permitido un grado de exhaustividad en las series mínimamente homogéneo. Lo cual, unido a sus diferenciales características ha aconsejado un tratamiento y agrupación de los datos variable, a saber:

Primeramente, se advertirá una falta de correlación en la periodicidad de las Medias Móviles. Entendemos justificado el uso modular 12 para la carne a fin de eliminar las referidas variaciones mensuales en su precio, que no hacen sino distorsionar los movimientos cíclicos de más larga duración. Para los restantes productos, sin embargo, se optó por una Media Móvil con módulo 14 referido al valor central ${ }^{43}$.

En segundo lugar, haremos notar que carne y vino constituyen las dos partidas más ricas de la documentación (2.382 y 2.424 registros, respectivamente), en razón de su compra mensual a lo largo del período en cuestión. Es por ello que permiten obtener un más preciso análisis de la variabilidad mensual, además de los restantes ritmos de cambio. Sabido es que el carácter perecedero del primero, y la dificultad de transporte del segundo serían los causantes de esta cadencia de adquisiciones, en tanto el trigo se vería beneficiado -en perjuicio de la investigación actual- de unas mayores posibilidades de almacenamiento ${ }^{44}$. Pero, al mismo tiempo, carne y vino son indicativos de diferentes ritmos económicos: el primero dá cuenta de la realidad económica comarcal; el

42. Un tan excelente catálogo documental de la variedad monetaria de la época como evidencia de la contravención de la legislación vigente sobre batimiento de moneda lo constituye el expediente judicial incoado por Nicolás de Lecea y José Ignacio Pizarro, Contrastes de Bilbo, sobre falsificación de moneda, donde se insertan diversas monedas defectuosas incautadas (de las que al presente, lógicamente, sólo los soportes se conservan). A.H.D.B.: Secc.Jud.: Corr.: Leg. 593, № 6 (1771/1778).

43. De acuerdo con A. EIRAS ROEL Y R. USERO GONZÁLEZ (1975: 656). Modalidad que permite una mejor percepción de la tendencia de las variaciones de larga duración en relación con las Medias Móviles de módulo 7; en tanto optimiza las de 14 centradas en el último dato de la serie al corregir el retraso en la captación del movimiento de la misma. Por supuesto, bien que buena parte de estos criterios sean para seriaciones de periodicidad anual, por nuestra parte ha sido -a falta de mejor argumentación- aplicado para datos mensuales.

44. J. LANGE (1996: 192). 
segundo lo hace de unos circuitos de mayor amplitud. Por otro lado, aún se podía discriminar una tercera categoría para aquéllos productos de procedencia ultramarina (i.e., bacalao, chocolate y cera) ${ }^{45}$.

De acuerdo con la aplicación del anterior principio, por extensión, al conjunto de los datos, hemos procedido a la agrupación -a diferencia de las habituales clasificaciones según la naturaleza del producto (i.e., agrícola vs. no-agrícola), ${ }^{46}$ en función de los circuitos de transporte, en consonancia con el modelo de P. VILAR ${ }^{47}$. Distinguimos, pues, las referidas tres categorías:

A) Productos originarios del Valle de Arratia: carne y maíz.

B) Productos procedentes del interior peninsular: vino, trigo y aceite.

C) Productos de abastecimiento marítimo: bacalao, chocolate y cera.

A) Autoconsumo: carne y maíz

Productos ambos generados en el horizonte comarcal, difieren en la categoría social de consumo, como también en la calidad de los datos.

GRÁFICO 1. Precios Carne y Maíz (MM. 12 y 14).

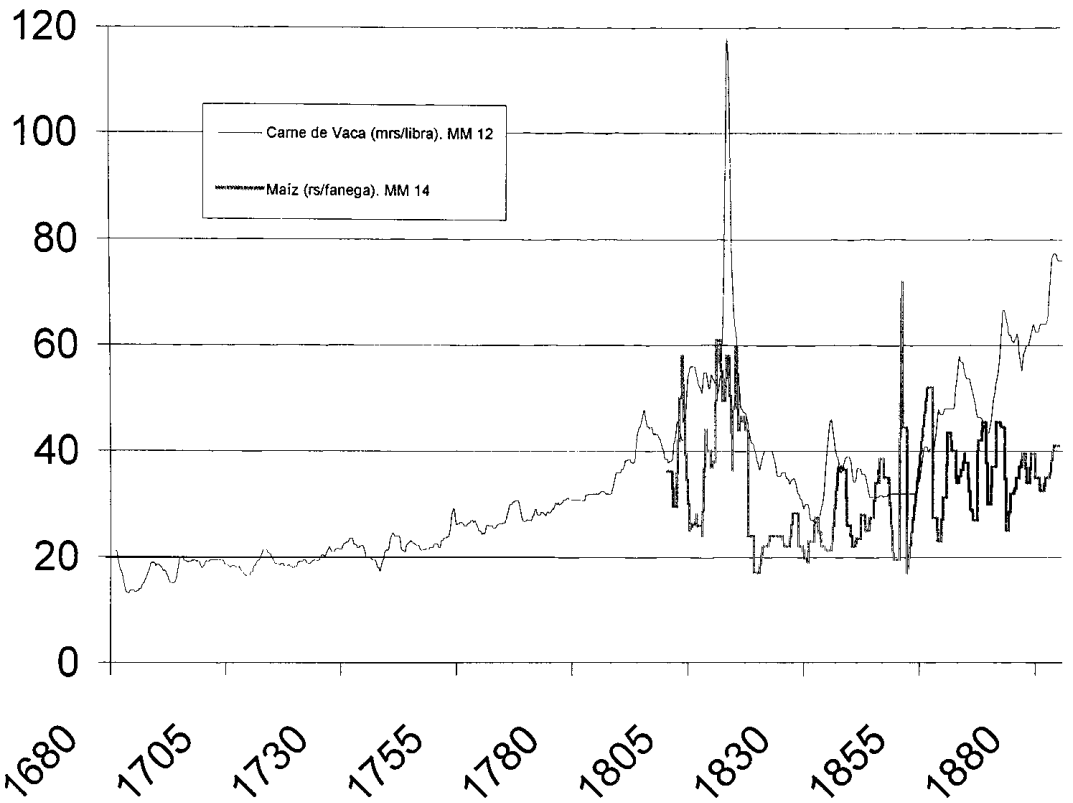

45. Ciertamente, es de justicia advertir los exíguos límites de fiabilidad de esta tercera serie $-353,128$ y 89 items, respectivamente.

46. W. ABEL (1974: 159-171), E. LABROUSSE (1980: 171-173), ó E.J. HAMILTON (1988: 205-223), por citar sólo algunos de los más renombrados.

47. P. VILAR (1987: 285-397). 
Entiéndase carne por vacuno, ya sea montesino o del valle, cuya diferente calidad se proyecta nítidamente en el gráfico, junto con su diferencial comercialización estacional (invierno/verano) ${ }^{48}$.

GRÁFICO 2. Datos originales carne 1685/1695

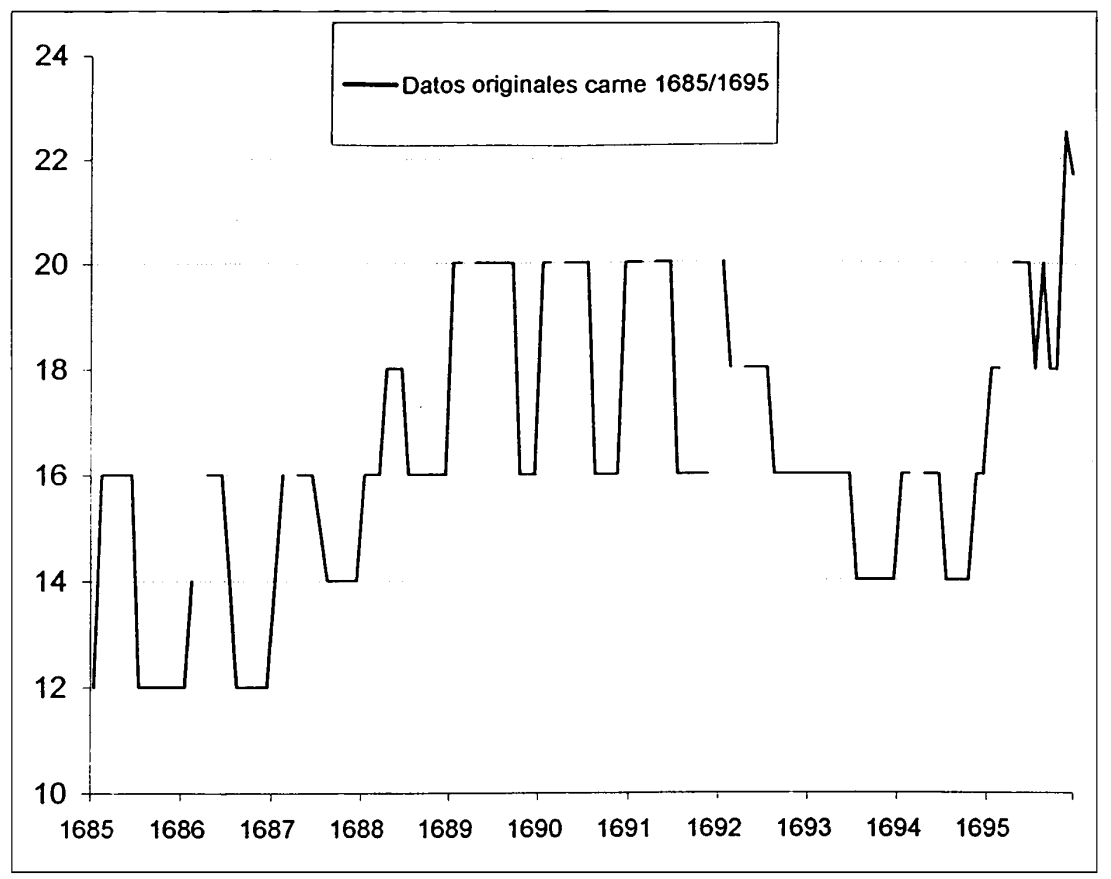

Sometido el abasto de carne a una estricta normativa municipal, su incremento será, en consecuencia, moderado y regular hasta el final de la centuria ilustrada. No cabe, pues, distinguir ciclo ninguno ${ }^{49}$. El aumento a lo largo de todo este período apenas Ilega a duplicar su valor, siendo más acelerado en la segunda mitad del Setecientos. Por el contrario, la incidencia de las conflagraciones bélicas finiseculares será grave y profunda: desde 1794 hasta el final de las Guerras Napoleónicas las alteraciones en el precio de la carne serán contínuas. Oscilaciones que alcanzarán niveles de intensidad sin parangón en los primeros meses de 1814 (momento en que la libra de vaca llegó a alcanzar un

48. La distinción entre ambas calidades de vacuno no tiene más razón de ser que el coste de su mantenimiento. Modelo este que ya fue detectado para Zeberio: J. LANGE (1996: 134).

49. Las ligeras ondulaciones de los primeros cuarenta, de 1755 -recuérdese la Matxinada de la Carne en Gipuzkoa- o de finales de los años sesenta resultan intranscendentes. En consecuencia, con ser el producto del que mayor número de entradas disponíamos, pudimos evidenciar su escasa expresividad, toda vez que únicamente recogía el proceso general de inflación; no ya los ciclos económicos de la villa. 
precio de 160 maravedís). Corolario lógico de la rapiña de tropas foráneas en movimiento, no será sino hasta 1819, en que -merced a una vertiginosa caídase recuperen los niveles de preguerra. Con todo, la depresión no cesará hasta la Primera Guerra Carlista, en que nuevamente se produce un aumento de los precios (si bien no excesivo ni en intensidad ni en duración). Tras la recuperación del equilibrio post-bélico asistimos a un largo período (1843/1854) de estancamiento, despues del cual nuevamente remontarán los precios de manera escalonada pero clara. Recuperación sólamente truncada en el contexto de la crisis de los últimos sesenta, culminados -como es sabido- en la Segunda Guerra Carlista, durante la cual se alcanzarán de nuevo niveles desconocidos desde tiempos napoleónicos. Claro que ahora ya estos 72 maravedís/libra no desintonizaban en demasía con respecto a los años precedentes, de modo que la incidencia de la última Carlistada -con ser más evidente que para otros productos- no se nos antoja decisiva en la delineación de la curva. Finalizada la contienda, además, se advierte la continuidad de la tendencia alcista.

Creemos poder paliar la falta de datos relativos al maíz para los primeros años de nuestro análisis toda vez que se ha de distinguir entre introducción más o menos irregular y esporádica de su cultivo, y difusión generalizada del mismo en detrimento del trigo como alimento cotidiano fundamental ${ }^{50}$. No vemos inconveniente en -grosso modo- paralelizar su difusión con la sistematización de su presencia en nuestras fuentes, a finales de la Centuria Ilustrada, bien que -recúerdese- en el caso de la Comunidad de Santa Isabel su utilización no haya sido precisamente idéntica a la del entorno láico. Por entonces, en el contexto de desestabilización bélica imperante, se conocerán fuertes oscilaciones de muy breve duración e importante amplitud (triplicación de precios: hasta 72 reales/fanega en 1815 .VIII). La pacificación internacional restauracionista conllevará la recuperación de los niveles de preguerra, al tiempo que permite una mejor percepción de los factores endógenos en la ondulación de la curva (v.g., cosechas mediocres de 1824/1825). La irrupción, una vez más, del periplo bélico en nuestros datos resulta tardía -1838/1839- y sin la virulencia del cambio de centuria último, diluyéndose en una serie de modulaciones de mayor amplitud, e incluso intensidad, que jalonan, con una duración aproximada bianual, las décadas de 1840/1870. En este contexto, la crisis general de los últimos sesenta, y la Segunda Guerra Carlista serán los últimos hitos delimitadores de puntos de inflexión dignos de mención.

50. El confusionismo interpretativo en busca de fechas extraordinariamente tempranas es común en la historiografía vasca: cf. L.Mํㅡㄹ BILBAO (1977: 168); J.M. GONZÁLEZ CEMBELLíN (1990: 89-110, esp. 99). Ultimamente, sin embargo, se está revisando la cuestión, retrasando su difusión hasta el siglo XVIII: A.M ${ }^{a}$ CANALES CANO (1997: 200); o R. CONDE FUERTE (1997: 104). 
B) Importaciones de la meseta: vino, trigo y aceite

GRÁFICO 3. Trigo, vino y aceite (M.M. 14).

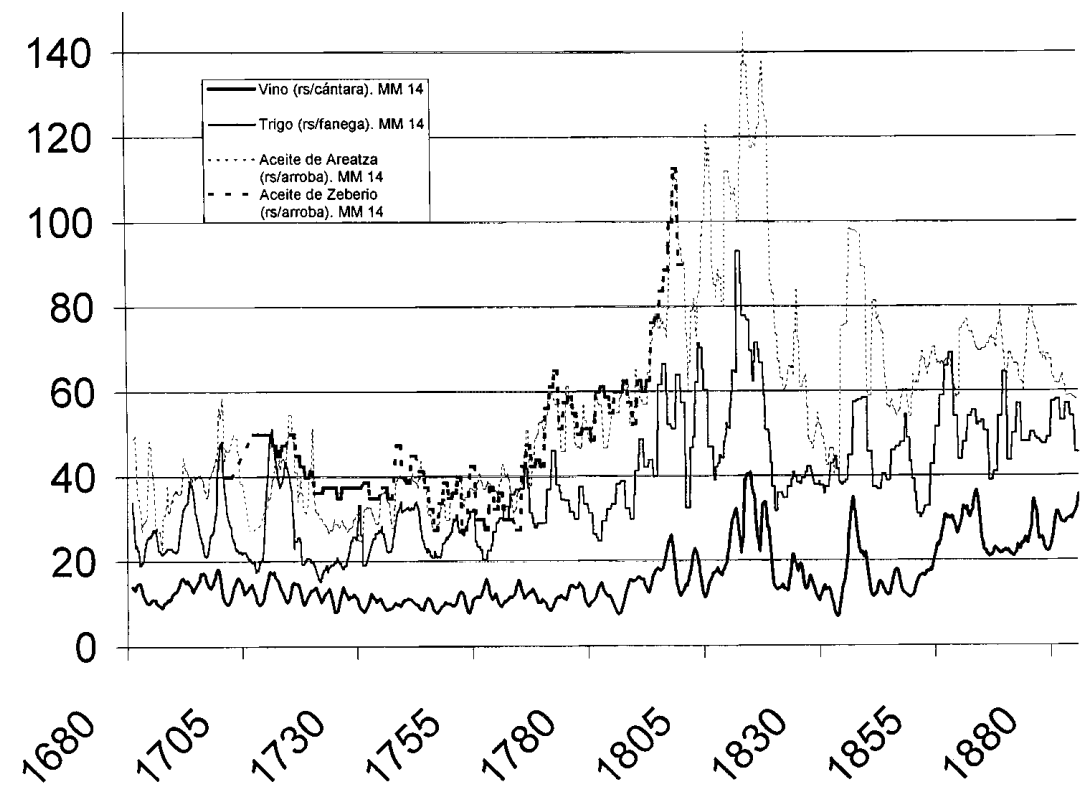

Por lo consiguiente al vino, éste experimenta ciertos movimientos cíclicos de cadencia y duración relativamente constantes durante los primeros decenios del estudio. Las fluctuaciones se atemperarán pasado el primer cuarto del Setecientos durante el resto de la centuria y hasta el colapso bélico final ${ }^{51}$. Entendemos tal mitigación como consecuencia de la variación en el status del producto, a resultas de la revolución del maíz. Difusión del mismo -en detrimento del trigo- que permitió no sólo un incremento de la productividad (i.e, eliminación del barbecho), sino también la roturación de espacios otrora destinados a pomaradas. En consecuencia, de la disminución de la tradicional producción doméstica de sidra se derivó una mayor integración del agro de Bizkaia, precisándose de mayores importaciones cerealísticas y vitivinícolas del interior (Araba y Nafarroa) ${ }^{52}$. Simultáneamente, a la inversa, estos productores agropecuarios del interior se encontraron a la altura de la primera mitad del Setecientos en la difícil tesitura de una reducción de la demanda de trigo en Bizkaia acompañada de una reducción del precio del mismo (situación no modificada sino hasta que, mediada la centuria,

51. En realidad la mitigación en el movimiento de los precios es un efecto de la utilización de Medias Móviles, como se aprecia en los datos originales. Vid. J. LANGE (1996: 193).

52. L.Ma BILBAO y E. FERNÁNDEZ DE PINEDO (1984: 142-144). 
el incremento demográfico alteró de nuevo los niveles de demanda). Encrucijada que se hubo de superar mediante una especialización vitivinícola ${ }^{53}$. Así, en Zeberio se triplicó el consumo de vino de Araba entre 1711 y $1731^{54}$; mientras en la zona meridional de Araba el blanco casi duplicó su producción entre 1666/1675 y 1720/173055; el múltiplo para el caso de Lizarra, por otro lado, se situó en el 2,5 entre 1720 y $1789^{56}$. A resultas, pues, de esta popularización de los caldos interiores creemos discriminar una disminución en su precio entre 1710 y 1730 , plenamente consolidada a mediados de siglo. Continuidad finalmente quebrada por una tendencia ascendente que, tímidamente, arranca de 1787, adquiriendo un nuevo empuje en 1793, para -tras sendos máximos en 1798 y 1803-alcanzar niveles excepcionales durante las Guerras Napoleónicas. Pero estos últimos máximos (duplicación de los niveles de precios anteriores), de intensidad relativamente moderada y duración equivalente, articulados por dos puntos de inflexión, aún proyectarán un último clímax finalizada la contienda. Con todo, y tras un impasse de recuperación de los niveles de preguerra, la Primera Guerra Carlista incidirá de manera más traumática que la anterior, a tenor de la subida experimentada durante estos años. Una vez más, la posguerra restaura los niveles previos, si bien ahora con escasa continuidad, por cuanto mediados los cincuenta se iniciará un aumento moderado pero constante que situará al vino en niveles máximos, que sólo ligeramente remitirán con la crisis de la segunda mitad de los sesenta -no recuperandose ya los índices primigenios-, para superar sin brusquedad la última confrontación bélica de la centuria pasada. Pero el ritmo sostenido de aumento del precio, iniciado décadas atrás, parecía ya imparable para los años siguientes.

A resultas de la progresiva sustitución del trigo en favor del maiz en la dieta diaria campesina, aquél modifica su naturaleza, convirtiendose, a la inversa del caso anterior, de manera gradual e imperceptible, en alimento de lujo reservado para las mesas más pudientes ${ }^{57}$, con la consiguiente distorsión en los niveles de precios. Aún más: además de la modificación en la capacitación social del producto, éste se nos presenta con frecuencia mezclado en forma de trigo "de la tierra" y de Araba, sin que sea posible en todas las ocasiones distinguir ambas calidades. El primero, de menor aprecio, resulta más infrecuente que el segundo, y siempre en partidas de escaso volúmen ${ }^{58}$, en razón del reducido monto exce-

53. Más allá de las valoraciones de que pueda ser objeto el incremento en la demanda de un producto de una mayor graduación alcohólica, hemos de señalar en su favor tanto su aporte calórico en las exíguas dietas medias, como -especialmente en el ámbito urbano- su carácter higiénico-sanitario, toda vez que el consumo de agua entrañaba no pocos riesgos de infección.

54. J. LANGE (1996: 180).

55. L.Ma BILBAO y E. FERNÁNDEZ DE PINEDO (1984: 146).

56. A. FLORISTÁN IMIZCOZ (1982: 254).

57. Cf. M. LARRAMENDI (1985: 65-66).

58. En 1709.XI se adquieren " 5 anegas de trigo con sus portes 170 reales (i.e., a 33,3 reales/fanega), que con una anega más de la tierra en 30 reales hacen 200 reales". 
dentario generado en el Valle. Con todo, es una reserva metodológica a tener en consideración en la ponderación de la fiabilidad de nuestros datos.

Mutatis mutandis, limitación igualmente extensible al aceite ${ }^{59}$, que se trae por lo general de Araba mediante arrieros y en grandes cantidades, en tanto algunas compras menores -a un precio por lo general muy superior- se efectuan en la abacería de Areatza $^{60}$.

El precio del trigo experimenta varias fluctuaciones de inusitada virulencia en el cambio de siglo -coyuntura de estancamiento agrícola previo a la Matxinada del Translado de las Aduanas ${ }^{61-}$. A partir de ahí, las oscilaciones ceden ligeramente en intensidad, aunque su presencia -en intervalos relativamente irregulares- es claramente perceptible. Pero al mismo tiempo, y de forma soterrada, tiene lugar en la segunda mitad del Setecientos un sutil aumento del precio, que nos sitúa, al comienzo de la década de los noventa, en niveles superiores a los iniciales (que, con todo, no llegarán todavía a duplicarlo). Interesa hacer notar, llegados a este punto, las analogías entre maíz y trigo: el marasmo de las guerras en el cambio de centuria genera análogos movimientos cíclicos, ya en intensidad como en duración, con una sincronía más que apreciable ${ }^{62}$. Normalizado el contexto internacional, la caída de los precios será rápida (aunque a inferior ritmo que en el caso del vino) y -una vez másnos repondrá los niveles de preguerra en 1819. La Carlistada de 1833/1839 dejará su huella en el gráfico, si bien con carácter tardío (a partir de 1838). Pero tal impronta será efímera, pues a partir de 1839 las fluctuaciones se intensificarán de nuevo, y en 1857/1858 -tras la muesca de la crisis general, a nivel internacional, de 1856- superarán con creces sus máximos. De intensidad y duración variables, estas fluctuaciones obviarán la Segunda Guerra Carlista, insertadas en sus propios ritmos de crecimiento sostenido, relativamente constante, con que se cerrarán los años seleccionados ${ }^{63}$.

59. Los datos del aceite de Zeberio proceden de A.M.Z.: Sto. Tomás de Olabarrieta, Fábrica 1695/1749 y A.H.E.B.: Zeberio, Sto. Tomás de Olabarrieta, Fábrica 1753/1802.

60. En 1713.II el precio del aceite acarreado fue de 38 reales/libra.; en tanto el de la abacería ascendió a 43,75 reales/libra. En estos casos, como en todos aquéllos de diferentes precios/calidades en una misma partida, hemos optado por su utilización siempre que se dispusiese de las cantidades adquiridas, aplicando el cociente del valor de la partida total entre el volúmen adquirido, entendiendolo más aproximativo de la realidad de las adquisiciones del Convento, que la media aritmética de los diferentes precios del producto (algunas partidas de precios desorbitantes eran completamente residuales).

61. Una visión de conjunto de la coyuntura económica del momento en J.J. LABORDA (1977: 136-181).

62. Las excepciones parciales de 1797/1798, 1810 y 1814 pueden obedecer a variaciones en los volúmenes cosechados, cierre de circuítos mercantiles, etc.

63. Para los años comentados, las principales variaciones se aprecian en 1837/1838, 1857, 1869, 1872 ó 1879/1880. 
Amplitud oscilatoria es, sin duda, la característica más llamativa de la serie del aceite, por cuanto se mantiene desde el inicio de la misma hasta su final. Difícilmente se puede, a primera vista, disociar los dos grandes aumentos de principios del Setecientos del trance de la guerra intermonárquica y la incidencia de la Matxinada del Translado de las Aduanas, respectivamente. Posteriormente los ciclos interanuales perderán vigor, para entrar en un impasse de estancamiento sostenido hasta mediar la centuria; a partir del cual se iniciará una etapa de crecimiento ininterrumpido acompañado de una mayor amplitud de variación. Crecimiento cuyo ritmo se acelerará a finales de Siglo, con ocasión del colapso bélico (máximo de 145 reales/arroba en 1813.VIII, valor doble a algunos índices del decenio anterior). Recuperados los niveles de preguerra ya para 1819 , la tendencia general -por el contrario- mantiene una tónica depresiva generalizada, únicamente truncada de manera brusca por efecto de la Primera Guerra Carlista (lógica, por otro lado, habida cuenta del frecuente corte en las relaciones comerciales con el interior peninsular, a resultas de los diversos avatares bélicos). Porque, el translado de las aduanas a la lengua de mar (R.D. de 29.X.1841) no parece haber incidido en el gráfico: quizás para entonces los niveles de cohesión con los mercados hispánicos tuvieran el suficiente vigor como para hacer la desaforada medida imperceptible en este punto. Mayor importancia parecen para ahora adoptar otros condicionantes -Guerra de Crimea en 1856, ó crisis de los últimos sesenta- que nos ponen de relieve la simultaneidad coyuntural (y, por ende, la integración) con otros mercados foráneos.

GRÁFICO 4. Aceites Areatza y Zeberio (M.M. 14).

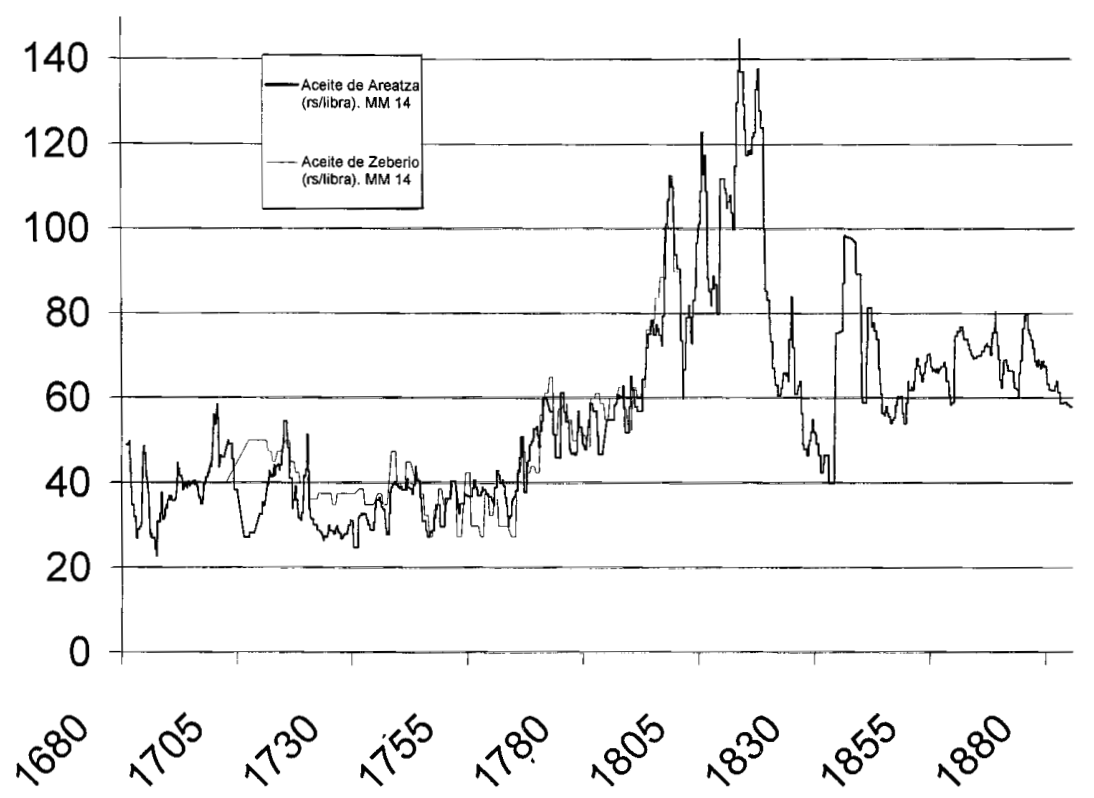


Análogas circunstancias concurren en la contrastación, a lo largo del período estudiado, de los precios de los aceites de Zeberio y Areatza, entendidos como reflejo de un proceso de integración comarcal -probablemente más ámplio y extensible a otros productos- en estructuras y circuítos mercantiles de mayores dimensiones, donde costos y ritmos de cambio sean más homogeneizables.

Retenga el lector, de cuanto se ha expuesto hasta ahora, el hecho de que las fluctuaciones experimentadas con posterioridad a los enfrentamientos con el francés ofrecen unos paralelismos nada despreciables entre carne, maíz, vino, trigo y aceite.

\section{C) El comercio de ultramar: bacalao, chocolate y cera}

Aquí nos encontramos ante ritmos generados por el mercado de Ultramar, procedencia asignable a todos ellos: Virginia, Noruega, Finlandia o Escocia (para el bacalao); Caracas o Guayaquil (chocolate); o Norte y Este de Europa (cera).

El número de partidas localizable en nuestras fuentes no ha sido, por desgracia, el deseado; distando considerablemente (máxime en los casos de chocolate y cera) del resto de los productos tratados. En el bacalao, además, hay que hacer constar una vez más el problema de la superposición de diferentes productos/calidades ${ }^{64}$.

GRÁFICO 5. Bacalao, chocolate y cera (M.M. 14).

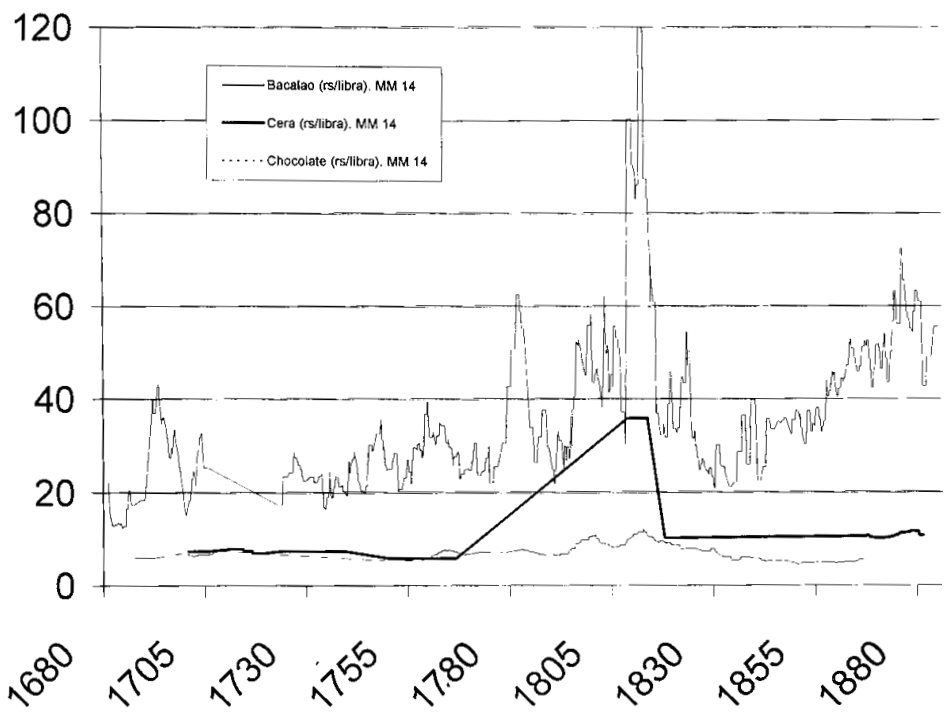

64. Por ejemplo, según procedencia: En1830.IX, de Escocia 21 reales/arroba, de Noruega 17,5 reales/arroba. En 1831.X, de Escocia 24 reales/arroba, de Noruega 21,5 reales/arroba. Añádase a ésto la cuestión de las compras marginales en la abacería de Areatza de cantidades menores a un precio más elevado... 
Explicar la evolución de la curva del bacalao en función de la coyuntura internacional es relativamente sencillo. El enfrentamiento franco-español de la Guerra de la Liga de Augsburgo encajaría, de esta manera, con las subidas de finales del Seiscientos, como la guerra intermonárquica hispana -con intervención de la flota inglesa desde 1702- lo haría a principios del Setecientos. Igualmente lo hacen los puntos de inflexión de los últimos treinta y parte de los cuarenta, y principios de los sesenta -recúerdense la oreja de Jenkins, la Sucesión de Austria o la intervención hispana contra Inglaterra en $1762^{65}$. Escasa virulencia, sin embargo, proyectaron los anteriores conflictos, en relación con los siguientes. Efectivamente, la nueva guerra hispano-inglesa de 1779/1783 dejará una profunda impronta en el gráfico. Huelga reiterar, con posterioridad, lo ya comentado en relación al ciclo revolucionario-napoleónico. Ya en pleno siglo XIX, finalmente, sobresalen los altibajos de ambas Carlistadas, consecuencia directa de las dificultades de abasto de tales productos.

Dejamos, por mor de no sobrecargar el contenido puramente descriptivo del texto, a la iniciativa del lector la contrastación formal descriptiva de la serie anterior con las de los productos de diferente procedencia. Las conclusiones a que nos han conducido, por nuestra parte, se exponen seguidamente. No sin antes advertir, finalmente, que aunque faltan datos para enjuiciar con mínimas garantías la evolución del chocolate y de la cera, no creemos que éstas disten demasiado de la del bacalao, toda vez que su comercialización se canalizaría a través de análogas redes ${ }^{66}$.

No queremos, sin embargo, dejar de hacer notar la imperceptible modificación en la naturaleza del chocolate experimentada probablemente entre 1820 y 1860. Recuérdese cómo ya desde 1520 México, Guatemala y Venezuela abastecían a la Metrópoli de este producto ${ }^{67}$. Consumo creciente ${ }^{68}$ en los siglos XVII y XVIII, durante los cuales su importación fué monopolizada por los holandeses, hasta-como es sabido- la fundación, por Real Cédula de 1728.IX.25, de la Real Compañía Guipuzcoana de Caracas, que se haría con este comercio, a consecuencia de lo cual el precio del producto se redujo a la mitad. Efectivamente, los cuarenta y ocho navíos de la Compañía debieron de contribuir decisivamente a la difusión del consumo chocolatero en Euskal Herria ${ }^{69}$. Entendemos que la transformación en el status de

65. No se advierte la incidencia del monopolio inglés de los caladeros de altura de Terranova, en perjuicio de la flota vasca, a resultas del Acuerdo de Utrecht (1713.IV.11).

66. Claro que siempre quedará pendiente la incógnita de la procedencia de la cera, por cuanto, teniendo constancia de la práctica de su importación, ignoramos exactamente la potencialidad de las aportaciones de la producción autóctona...

67. J.Maㅡ GORROTXATEGI PIKASARRI (1987: 146-199), a quien seguimos en las líneas inmediatas.

68. Con independencia de sus cualidades gastronómicas (bizcochos de soletilla o cucharra y agua de bolado), su utilización en los medios de la medicina popular, así como la favorable propaganda eclesiástica, incidieron notablemente en su difusión.

69. "En estos últimos cien años se pueden contar a cientos los que se han dedicado al oficio de chocolatero en el País Vasco. Por lo menos había uno en cada pueblo, y a docenas en 
un producto genera, en el tránsito de su consumo restringido a su carácter de masas, un lapso de sobreoferta, durante el cual se reduce considerablemente el precio del mismo. Para el caso que nos ocupa, insistimos en creer datar este tránsito en el período 1820/1860, articulado por el mínimo de 1850.VII (3,8 reales/libra).

\section{Representatividad de la serie de precios de Areatza. Extrapolación (y límites) para el análisis de la coyuntura económica de Bizkaia}

Los resultados de la exposición hasta este presente punto no remontan más allá del reducido ámbito de la Microhistoria, tanto en razón de las dimensiones del caso analizado, como de las posibilidades de comunicación -aparentemente, al menos- de nuestro núcleo en relación con el entorno circundante. Insatisfacción de la que la simple extrapolación de datos al conjunto territorial de Bizkaia en modo ninguno resulta a priori válida. La cuestión es clara: ¿en qué medida capitaliza Bilbo el abasto marítimo, manteniendo -al amparo de su dinámico comercio consular- unos precios más económicos que el resto del Señorío? O bien, a la inversa: ¿cuales son los niveles de integración/homogeneidad -si tales- alcanzados por los mercados locales? ¿Es este un concepto propio de la Contemporaneidad/Industrialización, o cabe remontarlo al Antiguo Régimen?

En cualquier caso, y a los efectos de ponderar la representatividad de la fuente objeto del análisis principal, hemos procedido a su contrastación con otras series de precios: Bilbo, Belandia, Lekeitio, Amoroto, Mendexa, Ereño y Ermua ${ }^{70}$ de trigo y maíz (trigo únicamente disponible, en el caso de Bilbo). Ciertamente, series todas ellas de menor riqueza que la de Areatza (i.e., un único precio anual, a excepción de Lekeitio, amén de la restricción de la amplia gama productiva objeto del análisis previo $)^{71}$. Pero la virtualidad de esta serie consiste en su amplitud espacial, donde se recogen nucleos rurales y urbanos, repúblicas costeras e interiores, y -por supuesto- el paradigmático caso de Bilbo, piedra angular del conjunto.

las grandes ciudades. Sólamente en Tolosa, en el año 1861, había diez chocolateros (...) En 1888 había en Pamplona cuarenta y tres chocolateros." J.Mํㅡㄹ GORROTXATEGI PIKASARRI (1987: 177).

70. Fuentes: Amoroto: A.H.E.B.: Amoroto, San Martín Obispo: Fábrica, cit. R. URIARTE AYO (1988: 275-276). Belandia: A.H.E.B.: Belandia, Sta. Eulalia: Fábrica, 1550/1878. Bilbo: Archivo Histórico del Convento de la Santa Cruz de Bilbo (A.H.C.S.C.B.): Libros de Cuentas, cit. M. MAULEÓN (1961: 206). Ereño: A.H.E.B.: Ereño, San Miguel Arcángel: Cofradía del Rosario, Cuentas, 1767/1951. Ermua: A.H.E.B.: Ermua, Santiago Apóstol: Fábrica, cit. J.A. PINEDO OTAOLA (1996). Lekeitio: 1ํ A.H.E.B.: Lekeitio, Sta. Må: Cabildo, Cuentas 1771/1836 y 1836/1918; Fábrica 1730/1780; 2º A.H.C.S.D.L.: Libro de Gastos, 1756/1850. Mendexa: A.H.E.B.: Mendexa, San Pedro Ad Víncula: Fábrica 1760/1843.

71. Incluso en este caso, el registro mensual de las adquisiciones de la mesa conventual de Santo Domingo mostró una menor riqueza que la serie de Areatza, toda vez que las partidas no indican en ocasiones cantidad o precio del suministro, imposibilitando -en consecuenciasu cálculo a partir del monto total devengado. Cuestión ésta que corrobora -creemos- el tratamiento dado a nuestros materiales, habida cuenta de la calidad excepcional de la documentación de Santa Isabel. 
No parece este un ejercicio metodológicamente reprobable. Ya P. VILAR (1987: 289) se mostaba precabido en la extrapolación de sus conclusiones en base a precios del Hospital de Sta. Creu (Barcelona) para el conjunto de Cataluña. Contrástese igualmente, en este sentido, el ímprobo esfuerzo documental de E.J. HAMILTON (1988: 26-27; 130), así como sus reservas metodológicas acerca de la generalización de conclusiones. Entendemos, por el contrario, más arriesgado -y por nuestra parte, no ejercido- el cálculo de la evolución de los precios genéricos del territorio a través del promedio de diversas series locales, tal y como se ha propuesto para Gipuzkoa ${ }^{72}$.

He aquí, pues, nuestros resultados ${ }^{73}$ :

GRÁFICO 6. Maíz Bizkaia, 1750/1850 (M.M. 24).

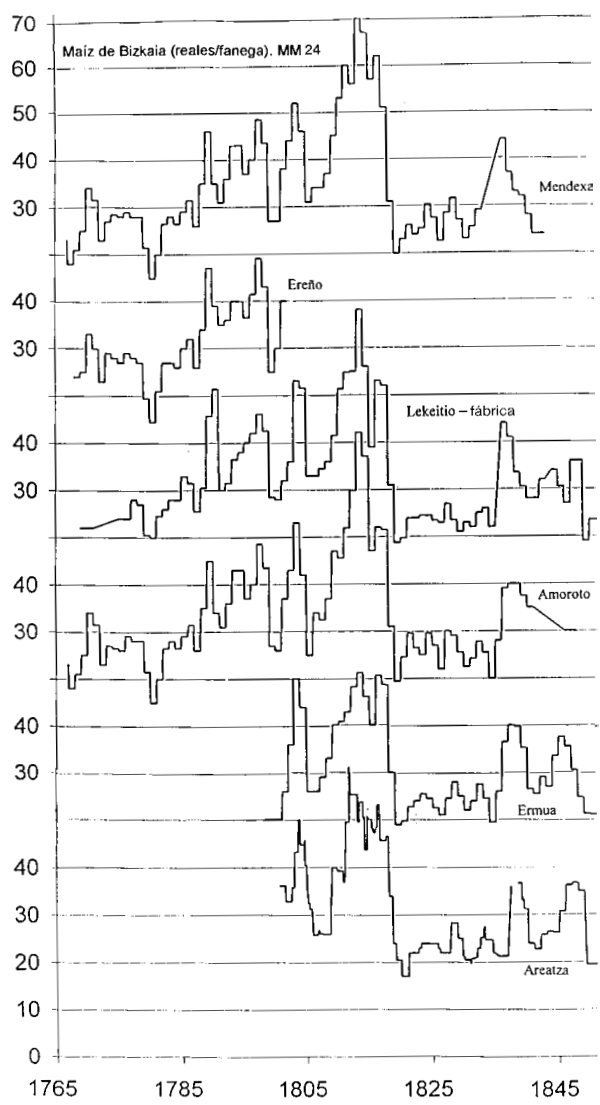

72. S. PIQUERO ZARAUZ, I. CARRIÓN ARREGUI, I. MUGARTEGUI EGUÍA (1998: 445). Los propios autores manifiestan sus reservas acerca de la representatividad de los datos...

73. Advertimos del empleo de Medias Móviles de módulo 24, al efecto de ponderar la tendencia evolutiva general de series de dato único anuales con los datos mensuales de Areatza. 
La naturaleza autóctona del producto nos sitúa en el horizonte del más fiel indicador de los ritmos de cambio del entorno territorial objeto de estudio, por permanecer completamente ajeno a las alteraciones que factores externos (no siempre susceptibles de discriminación de aquellos otros propios del importador) pudieran haber introducido en el devenir de los foráneos.

De la contrastación de las diferentes series registradas, sobresalen -sin apenas género posible de duda- las similitudes sobre las disimilitudes. Porque si éstas se limitan a la intensidad y amplitud de las oscilaciones, las tendencias generales -con unos mínimos márgenes de confianza en los puntos de inflexión- se reproducen sistemáticamente en todas las series. De donde puede inferirse una más que notable homogeneidad en los niveles de precios $-\mathrm{y}$, por extensión, en la evolución económica coyuntural- de un ámplio espectro territorial del Señorío de Bizkaia desde -cuando menos- mediados del Setecientos. Con todo, ello no reporta -por el momento- hipótesis ninguna referente a Bilbo; además de que todavía se podrá argüir en nuestro contra el sesgado y restringido carácter de los argumentos esgrimidos.

Serie de amplitud cronológica notable, interesa retener aquí la contrastación evolutiva de los precios de Areatza, Bilbo y Amoroto. Y es que desde tiempos extraordinariamente tempranos se advierte una marcada sincronía evolutiva entre tales enclaves (ya en las propias tendencias, como en duración e intensidad de las mismas); lo cual redimensiona el análisis de los precios de Santa Isabel (recuérdese, por otro lado, la mayor riqueza documental de esta fuente). Efectivamente, nuestra hipótesis inicial cobra vigor a medida que la presencia de nuevos datos a partir de mediados del XVIII evidencia una notable correlación en las oscilaciones de todas las series, únicamente variable - grosso modoen amplitud, persistencia, cronología de los puntos de inflexión y promedios generales. Dejando al márgen las tres primeras, por cuanto no entraremos de nuevo en casuística descriptiva (a todas luces secundaria del hilo argumental presente); conviene hacer notar, a propósito de los últimos, niveles más elevados en Ermua -hasta principios del Ochocientos; momento a partir del cual la tendencia dominante será precisamente la inversa- y (especialmente) Belandia con relación a los restantes municipios. Hecho que, si bién puede ser parcialmente atribuíble a la ubicación periférica portuaria de ambos núcleos (más en relación con la realidad económica del Valle del Deba y de Araba, respectivamente), difícilmente resulta ésta satisfactoria - para el segundo caso, al menosa tenor de la mayor proximidad de Belandia con los núcleos productores cerealísticos interiores. Sea como fuere, y aún cuando la hipótesis no deba ser tomada por definitiva, proponer un elevado nivel de homogeneidad de precios para el conjunto territorial de Bizkaia, desde inicios de la Centuria Ilustrada, cuando menos, y donde los índices de Bilbo no marcaran la pauta dominante, resulta relativamente razonable, a tenor de los datos anteriores. De donde cabe deducir, en consecuencia, una cierta homogeneidad en los niveles de precios 
del trigo, independientemente de las rutas a través de las que se canalice su importación ${ }^{74}$.

GRÁFICO 7. Trigo Bizkaia, 1700/1850 (M.M. 24)

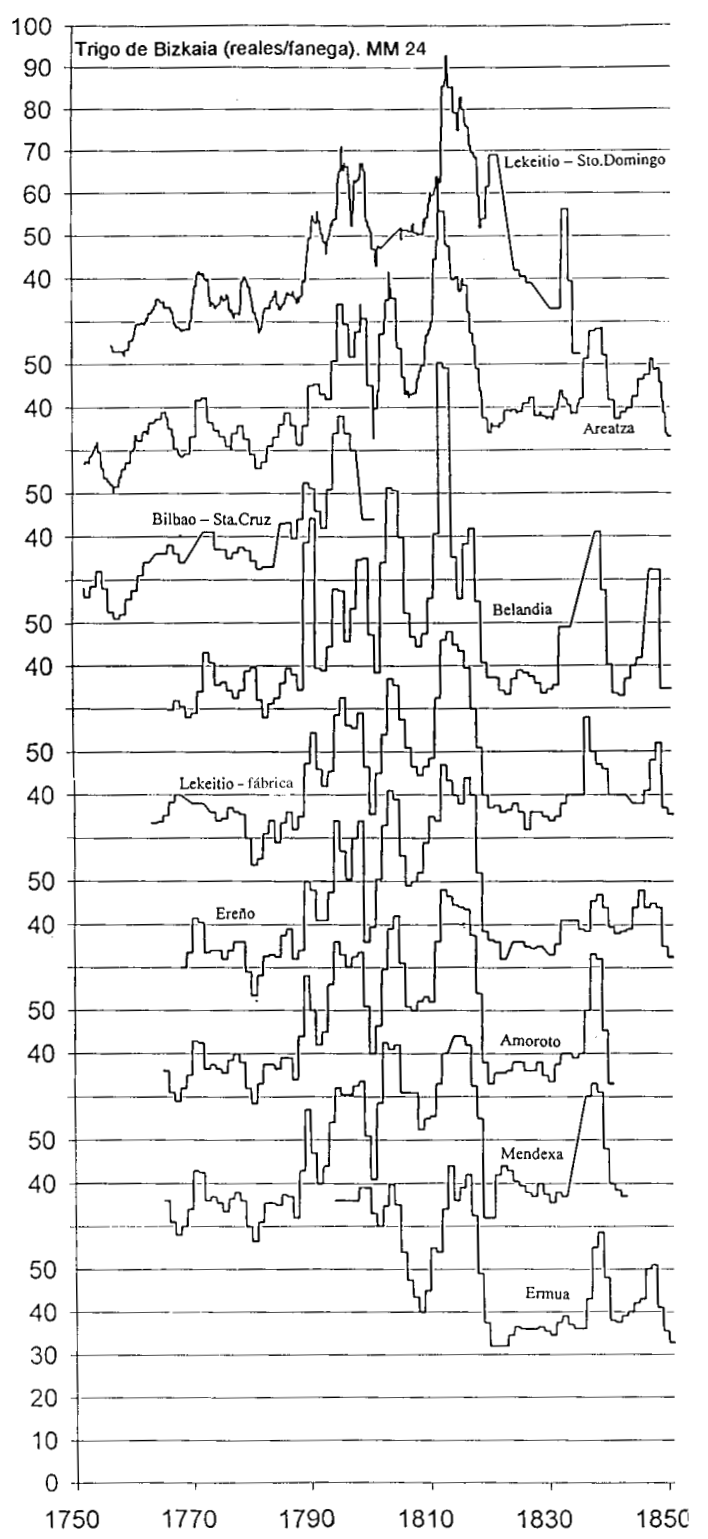

74. En cuanto a las relaciones agro-urbanas, finalmente, parece apreciarse para el caso del entorno del Lea -aunque sólo para la segunda mitad del Setecientos- una mayor carestía en las 


\section{Conclusiones}

1ํ La discriminación de categorías en el análisis de los precios en función de la procedencia de la producción es una metodología de trabajo válida, y conducente a nuevas perspectivas en la historia de los precios.

$2^{\text {o }}$ La inflación monetaria como variable periodizadora durante el perído considerado (continuación directa, por otro lado, de la época de la llamada revolución de los precios) genera dos fases -1685/1782 y 1782/1880 - en función de su mayor o menor presencia.

$3^{\text {o }}$ La incidencia diferencial de la inflación monetaria (i.e., más acusada durante el Seiscientos, y a partir de 1782) difumina la presencia de otros factores -para el caso analizado, el transporte- que coadyuvan a explicar los ritmos de cambio de los precios.

4ํ Los parámetros en que se opera por medio de las corrientes tradicionales -Cuantitativismo/Fiscalismo- resultan, a nuestro entender, tanto insuficientes cuanto desenfocados, toda vez que no se toman en consideración estos otros factores, que -de desigual presencia e incidencia- actúan asimismo según regiones y épocas.

$5^{\text {o }}$ Los niveles de integración alcanzados en el conjunto del Señorío de Bizkaia a principios del Setecientos no permiten dicotomizar la evolución general de los precios en Bilbo de la del resto de Bizkaia. Como quiera que los índices de precios ofrecen ligeras variaciones entre sí, más determinante que éstas se nos antojan las variaciones coyunturales de que dan cuenta.

6ํㅡㄹ El análisis de la coyuntura económica de Areatza realizado puede ser -en líneas generales y sin ánimo de conversión automática en tal- extrapolado al conjunto de la Bizkaia Antiguorregimental, en especial en materia de seguimiento del devenir económico y sus ritmos. E insistimos en destacar la relevancia del modelo porque difícilmente se hallarán fuentes de la riqueza de la analizada.

\section{Fuentes}

I) Archivo Histórico del Convento de Santa Isabel de Areatza (A.H.C.S.I.A.): Libro de Ingresos y Gastos 1665/1683, Libro de Ingresos y Gastos 1683/1695, Libro de Ingresos y Gastos 1695/1714, Libro de Gastos 1714/1726, Libro de Gastos 1726/1755, Libro de Gastos

anteiglesias circunvecinas (Amoroto, Mendexa) en comparación con los índices de la villa de Lekeitio. Cuestión, por otro lado, perfectamente lógica en razón de la mayor disponibilidad documental para este entorno... 
1755/1773, Libro de Gastos 1773/1833, Libro de Gastos 1833/1879, Libro de Gastos 1879/1946.

II) Archivo Histórico del Convento de Santo Domingo de Lekeitio (A.H.C.S.D.L.): Libro Becerro 1799/1833, Libro de Gastos 1756/1850.

III) Archivo Histórico del Convento de San José de Loiu (A.H.C.S.J.L.): Libros de Ingresos y Gastos 1796/1853.

IV) Archivo Histórico Provincial de Bizkaia (A.H.P.B.): Notariado: Esc. Pedro de Bedia Olaechea (Durango): Leg. 72 (1633); Esc. Miguel Ibáñez de Arteaga (Durango): Leg. 126 (1670); Esc. Antonio de Arbaiza (Durango): Leg. 151 (1701).

V) Archivo Histórico de la Diputación de Bizkaia (A.H.D.B.): Sección Administrativa: Estadísticas de Población I: Reg. 24, Sección Administrativa: Estadísticas de Población I: Reg. 50, Sección Judicial: Corregimiento: Leg. 593 № 6 (1771/1778), Sección Varios: Libros Históricos № 128: Censo de Thouvenot.

VI) Archivo de la Casa de Juntas de Gernika (A.C.J.G.): Archivo Bajo: Estadísticas de Población: Censo de Policía: Reg. 20.

VII) Archivo Municipal de Zeberio (A.M.Z.): Zeberio, Sto. Tomás de Olabarrieta, Fábrica 1695/1749.

VIII) Archivo Histórico Eclesiástico de Bizkaia (A.H.E.B.): Belandia, Sta. Eulalia: Fábrica 1550/1878; Ereño, San Miguel Arcángel: Cofradía del Rosario, Cuentas 1767/1951; Lekeitio, Sta. Má: Cabildo, Cuentas 1771/1836 y 1836/1918; Fábrica 1730/1780; Mendexa, San Pedro Ad Víncula: Fábrica 1760/1843; Zeberio, Sto. Tomás de Olabarrieta: Fábrica 1753/1802.

\section{Fuentes impresas y bibliografía}

ABEL, W. (1966): Agrarkrisen und Agrarkonjunktur -Eine Geschichte der Landund Ernährungswirtschaft Mitteleuropas seit dem hohen Mittelalter Hamburg (reed. de 1935)

ABEL, W. (1974): Massernarmut und Hungerkrisen im vorindustriellen Europa Versuch einer Synopsis Hamburg

BARCENILLA, M.A. (1985): “De rentista feudal a rentista de capital. El Convento de la Santísima Trinidad de Orereta como agente económico. 18431905" In Eusko Ikaskuntza. Ataleko Koadernoak. Geografia-Historia 6

BILBAO, L.Maㅗ (1977): "Crisis y reconstrucción de la economía vascongada en el siglo XVII" In Saioak 2

BILBAO, L.Ma; Y FERNÁNDEZ DE PINEDO, E. (1984): "La producción agrícola en el País Vasco Peninsular, 1537/1850. Tendencia general y contrastes comarcales. Una aproximación" In Eusko Ikaskuntza. Ataleko Koadernoak. Geografia-Historia 2 
CANALES CANO, A.Maㅗ (1997): Orduña Bilbo: Bizkaiko Foru Aldundia

CATALÁN MARTÍNEZ, E. (1995): "La explotación del bosque por las iglesias vizcaínas, 1580-1770" In DONEZAR, J.Ma; Y PÉREZ LEDESMA, M. (Eds.): Antiguo Régimen y Liberalismo. Homenaje a Miguel Artola. Tomo II. Economía y Sociedad Madrid: Alianza

CIFUENTES PAZOS, J.M. (1994): El papel económico de la iglesia vizcaína en el ámbito parroquial Bilbo: Universidad de Deusto (tesis doctoral inédita)

CONDE FUERTE, R. (1997): Orozko Bilbo: Bizkaiko Foru Aldundia

EIRAS ROEL, A.; Y USERO GONZÁLEZ, R. (1975): "Precios de los granos en Santiago de Compostela y Mondoñedo: siglo XVIII" In Actas de las I Jornadas de Metodología Aplicada de las Ciencias Históricas. Tomo III. Metodología de la Historia Moderna. Economía y Demografía Vigo: Universidad de Santiago

FERNÁNDEZ DE PINEDO, E. (1974): Crecimiento económico y transformaciones sociales del País Vasco (1100-1850) Madrid: Siglo XXI

FLORISTÁN IMIZCOZ, A. (1982): La Merindad de Estella en la Edad Moderna: los hombres y la tierra Irunea: Príncipe de Viana

GONZÁLEZ CEMBELLÍN, J.M. (1990): "La introducción y difusión del maiz en el Concejo de Güeñes" In Eusko Ikaskuntza. Ataleko Koadernoak. Geografia-Historia 17

GORROTXATEGI PIKASARRI, J.Ma (1987): Historia de la confitería y repostería vasca. Tomo I Donostia

HAMILTON, E.J. (1988): Guerra y precios en España. 1651-1800 Madrid: Alianza

I.N.E. (Ed.)(1988): Censo de 1787. Floridablanca Madrid: Artes Gráficas

ITURRIZA, J.R. (1985): Historia General de Vizcaya Bilbo: Amigos del Libro Vasco (reed. facsímil de 1885)

LABORDA, J.J. (1977): "El arranque de un largo protagonismo: la recuperación comercial de Vizcaya a comienzos del siglo XVIII" In Saioak 2

LABROUSSE, E. (1980): Fluctuaciones económicas e historia social Madrid: Tecnos (reed. de 1962)

LANGE, J. (1996): Economía rural tradicional en un valle vasco. Sobre el desarrollo de estructuras mercantiles en Zeberio en el siglo XVIII Bilbo: Beitia

LANGE, J. (2000): "Y se hizo la luz: cera y aceite en las iglesias de Zeberio" In MIEZA, R. Ma y GRACIA, J. (Eds.): Haciendo historia. Homenaje a $M^{a} A$. Larrea. Bilbo: E.H.U.

LARRAMENDI, M. (1985): Corografía de la Muy Noble y Muy Leal Provincia de Guipúzcoa Bilbo: Amigos del Libro Vasco (reed. de 1754)

LE PLAY, F. (1990): Campesinos y pescadores del Norte de España Madrid: Ministerio de Agricultura, Pesca y Alimentación

MADOZ, P. (1990): Diccionario Geográfico-Estadístico-Histórico. Valladolid: Ambito (reed. facsímil de 1845)

MARTÍNEZ RUEDA, F. (1994): Los Poderes Locales en Vizcaya. Del Antíguo Régimen a la Revolución Liberal (1700-1853). Bilbo: E.H.U. 
MAULEÓN, M. (1961): La población de Bilbao en el Siglo XVIII Valladolid: Universidad de Valladolid

METZ, R. (1994): Geld, Währung und Preisentenwicklung- Der Niederrheinraum im europäischen Vergleich 1350-1800 Frankfurt a.M.: Fritz Knapp Verlag

MUTILOA, J. Ma (1984): La desamortización en Vizcaya Bilbo: Caja de Ahorros Vizcaína

NADAL OLLER, J. (1959): "La revolución de los precios españoles en el siglo $\mathrm{XVI}$ " In Hispania

PIEPER, R. (1985): Die Preisrevolution in Spanien (1500-1640). Beiträge zur Wirtschafts- und Sozialgeschichte Wiesbaden: Steiner Verlag

PINEDO OTAOLA, J.A. (1996): Ermua, Mallabia y Zaldibar Bilbo: Bizkaiko Foru Aldundia

PIQUERO ZARAUZ, S.; CARRIÓN ARREGUI, I.; MUGARTEGUI EGUÍA, I. (1998): "La revolución de los precios en Guipúzcoa del siglo XVI: los precios del trigo" In DÍAZ DE DURANA, J.R. (Ed.): La lucha de bandos en el País Vasco: de los Parientes Mayores a la Hidalguía Universal. Guipúzcoa, de los bandos a la Provincia (siglos XIV-XVI) Gasteiz: E.H.U.

RAMOS, F. (1987): "Algunos caracteres sociodemográficos de Arratia a fines del Antiguo Régimen" In II. Euskal Mundu Biltzarra. IV. Alea. Aintzinako Erregimenaren Krisia Donostia: Txertoa

REAL ACADEMIA DE LA HISTORIA (1980): Diccionario Histórico-Geográfico del País Vasco. Tomo IV Bilbo: L.G.E.V. (reed. facsímil de 1802)

URIARTE AYO, R. (1988): Estructura, desarrollo y crisis de la siderurgia tradicional vizcaína (1700-1840) Bilbo: E.H.U.

VILAR, P. (1972): Oro y moneda en la historia Barcelona: Ariel

VILAR, P. (1983): Crecimiento y desarrollo Barcelona: Ariel

VILAR, P. (1987): Cataluña en la España Moderna. Tomo II. Las Transformaciones Agrarias Barcelona: Crítica

YBARRA Y BERGÉ, J. (1967): Escudos de Vizcaya. Tomo III. Merindades de Marquina, Zornoza, Arratia-Bedia, Orozco y Ciudad de Orduña Bilbo: Villar. 